Cambridge University Press

0521549434 - Reducing the Stigma of Mental Illness: A Report from a Global Programme of the World Psychiatric Association

Norman Sartorius and Hugh Schulze

Frontmatter

More information

\title{
Reducing the Stigma of Mental Illness
}

The stigma attached to mental illness is the main obstacle to better mental health care and better quality of life for people who have the illness, for their families, for their communities and for health service staff who deal with psychiatric disorders. Stigma is pernicious and there are indications that, despite advances of psychiatry and medicine, it continues to grow and have more and often terrible consequences for patients and families.

In 1996, the WPA began an international programme to fight the stigma and discrimination associated with schizophrenia. The 'Open the Doors' programme has been implemented since then in more than 20 countries and has involved about 200 different anti-stigma interventions.

This book details the results of these international efforts and provides recommendations and guidance for those seeking to join this initiative or to start similar efforts for dispelling stigma and discrimination.

Norman Sartorius is one of the most prominent and influential psychiatrists of his generation. He has served as Director of the Division of Mental Health at the World Health Organization, and subsequently as President of the World Psychiatric Association. He is a member of the Council of the World Psychiatric Association and of the Expert Advisory Panel of the World Health Organization. He is an honorary professor of the University of London, a professor at the Universities of Zagreb and Prague and has held or holds professorial appointments at the Department of Psychiatry of the University of Geneva and at several other universities in Europe, the USA and China; he is a senior associate of the Faculty of the Johns Hopkins School of Public Health in Baltimore. He has written over 300 scientific papers and has authored, co-authored or edited more than 40 books.

Hugh Schulze is President and CEO of c|change Inc., a marketing communications company in Chicago, USA. His 25-year career in the communications field has included work in many industries, including healthcare and experience in all media. For the last 10 years, he has served as Communications Consultant for the 'WPA Global Programme to Fight the Stigma and Discrimination because of Schizophrenia' and has spoken at conferences and congresses internationally. He is also Consultant for the WPA Global Child Mental Health Programme. 
Cambridge University Press

0521549434 - Reducing the Stigma of Mental Illness: A Report from a Global Programme of the World Psychiatric Association

Norman Sartorius and Hugh Schulze

Frontmatter

More information

\section{Reducing the Stigma of Mental Illness}

A Report from a Global Programme of the World Psychiatric Association

Norman Sartorius

and

Hugh Schulze 
Cambridge University Press

0521549434 - Reducing the Stigma of Mental Illness: A Report from a Global Programme of the World Psychiatric Association

Norman Sartorius and Hugh Schulze

Frontmatter

More information

\author{
CAMBRIDGE UNIVERSITY PRESS \\ Cambridge, New York, Melbourne, Madrid, Cape Town, Singapore, São Paulo
}

CAMBRIDGE UNIVERSITY PRESS

The Edinburgh Building, Cambridge CB2 2RU, UK

Published in the United States of America by Cambridge University Press, New York

www.cambridge.org

Information on this title: www.cambridge.org/9780521549431

(C) Cambridge University Press 2005

This book is in copyright. Subject to statutory exception and to the provisions of relevant collective licensing agreements, no reproduction of any part may take place without the written permission of Cambridge University Press.

First published 2005

Printed in the United Kingdom at the University Press, Cambridge

A record for this book is available from the British Library

ISBN-13: 9780521549431 paperback

ISBN-10: 0521549434 paperback

Cambridge University Press has no responsibility for the persistence or accuracy of URLs for external or third-party internet websites referred to in this book, and does not guarantee that any content on such websites is, or will remain, accurate or appropriate.

Every effort has been made in preparing this book to provide accurate and up-to-date information that is in accord with accepted standards and practice at the time of publication. Nevertheless, the authors, editors and publisher can make no warranties that the information contained herein is totally free from error, not least because clinical standards are constantly changing through research and regulation. The authors, editors and publisher therefore disclaim all liability for direct or consequential damages resulting from the use of material contained in this book. Readers are strongly advised to pay careful attention to information provided by the manufacturer of any drugs or equipment that they plan to use. 
Cambridge University Press

0521549434 - Reducing the Stigma of Mental Illness: A Report from a Global Programme of the World Psychiatric Association

Norman Sartorius and Hugh Schulze

Frontmatter

More information

\section{Contents}

Preface

page $\quad \mathrm{xi}$

Introduction

xiii

Structure of this Book

xix

Participants in the Programme

$\mathrm{xxi}$

Acknowledgements

$\mathrm{XXV}$

\section{Developing the Programme}

What conceptual framework should the programme adopt?

The vicious cycle of stigmatization

Focus on schizophrenia or on mental illness in general?

Who should carry out the programme on country level? $\quad 7$

How should the activities of the programme be selected? $\quad 7$

What administrative structure should the programme have? 8

How long should the programme last?

What relationship should there be with other efforts dealing with

problems of stigma and discrimination?

How should the programme be evaluated? 10

References

Phase I Calgary, Alberta, Canada

Calgary, Alberta

Health care professionals

Emergency room professionals

Medical students, senior health care policy-makers and general health professionals

Teenagers: students in grades 9 and 11

The Teens Talking 2 Teens Competition 
Cambridge University Press

0521549434 - Reducing the Stigma of Mental Illness: A Report from a Global Programme of the World Psychiatric Association

Norman Sartorius and Hugh Schulze

Frontmatter

More information

vi Contents

Community Change Agents and opinion leaders 24

Who is the general public?

Conclusion $\quad 29$

Bibliography - Canada $\quad 31$

Phase II

3

Spain 35

Working from the inside out

Interventions for individuals living with schizophrenia and their families $\quad 38$

Health care institutions $\quad 38$

An approach to the public

Results $\quad 40$

Bibliography - Spain $\quad 41$

$4 \quad$ Austria $\quad 42$

Establishing a benchmark $\quad 43$

Targeting journalists $\quad 43$

Educating high school students $\quad 44$

Broadening the audience $\quad 44$

$\begin{array}{ll}\text { Mental health services } & 45\end{array}$

Conclusions $\quad 45$

Bibliography - Austria

\begin{tabular}{lr} 
Phase III & 47 \\
\hline
\end{tabular}

5 Germany $\quad 49$

Düsseldorf $\quad 51$

Interventions undertaken since 2000

The first 'Anti-stigma Prize' in Germany 52

Anti-stigma Training Modules 52

Competence Centre for Destigmatization of People with

Schizophrenia 53

Hamburg 53

Itzehoe-Steinburg and Kiel

Leipzig $\quad 54$

Interventions based upon Focus Group results: secondary school students $\quad 55$

Adult education $\quad 56$

Media $\quad 56$ 
Cambridge University Press

0521549434 - Reducing the Stigma of Mental Illness: A Report from a Global Programme of the World Psychiatric Association

Norman Sartorius and Hugh Schulze

Frontmatter

More information

vii

Contents

Munich 56

Conclusion

References - Germany

Bibliography - Germany

6

Italy

Research

Stigma and high school students

Stigma and journalists

Working with employers and their employees

Conclusion

References - Italy

Bibliography - Italy

7

Greece

A unique national opportunity

Mental health professionals

Working with the media

Expanding the volunteer network $\quad 73$

Stigma and the arts

Support materials for communication $\quad 75$

Stigma and high school students $\quad 76$

Individuals living with schizophrenia and families $\quad 76$

$\begin{array}{ll}\text { Local networking and awareness } & 77\end{array}$

$\begin{array}{ll}\text { Conclusion } & 77\end{array}$

Bibliography - Greece $\quad 78$

$8 \quad$ United States 80

Employers $\quad 81$

Criminal justice system $\quad 82$

Media and the general public $\quad 84$

High school students: reaching beyond schools $\quad 84$

Conclusion $\quad 85$

Bibliography - United States $\quad 86$

$9 \quad$ Poland $\quad 88$

Putting the structure in place $\quad 88$

Assessing needs $\quad 89$

A national perspective $\quad 90$

A non-governmental organization dedicated to schizophrenia 90

$\begin{array}{ll}\text { Teachers and students } & 91\end{array}$ 
Cambridge University Press

0521549434 - Reducing the Stigma of Mental Illness: A Report from a Global Programme of the World Psychiatric Association

Norman Sartorius and Hugh Schulze

Frontmatter

More information

viii

Contents

Employers $\quad 91$

Church and clergy $\quad 91$

A Day of Solidarity $\quad 92$

Conclusion $\quad 93$

Bibliography - Poland 94

10

Japan 95

Follow-up research on effectiveness 96

Study 1: Japanese psychiatrists 96

Study 2: Individuals diagnosed with schizophrenia 97

Study 3: Family members $\quad 97$

Study 4: General public/college students $\quad 97$

Study 5: Psychiatric professionals in universities $\quad 98$

Guidelines for the future $\quad 98$

Working in the community 99

$\begin{array}{ll}\text { Tokachi } & 100\end{array}$

Sendai 100

Okayama 101

$\begin{array}{ll}\text { Moving forward } & 102\end{array}$

References - Japan 103

Bibliography - Japan 103

$\begin{array}{ll}\text { Phase IV } & 105\end{array}$

11 Slovakia 107

$\begin{array}{ll}\text { Starting in Michalovce } & 107\end{array}$

Changing, not fighting, the system 109

Working with and through the media 109

$\begin{array}{ll}\text { Conclusion } & 110\end{array}$

References - Slovakia $\quad 111$

12 Turkey 112

Building a programme and a non-governmental organization 113

$\begin{array}{ll}\text { General practitioners } & 113\end{array}$

Working with the general public $\quad 114$

$\begin{array}{ll}\text { Consumer and family members } & 115\end{array}$

High school students and teachers $\quad 115$

$\begin{array}{ll}\text { Conclusion } & 116\end{array}$

Bibliography - Turkey 116 
Cambridge University Press

0521549434 - Reducing the Stigma of Mental Illness: A Report from a Global Programme of the World Psychiatric Association

Norman Sartorius and Hugh Schulze

Frontmatter

More information

\section{ix Contents}

13 Brazil 117

Establishing the programme 117

Targeting two communities $\quad 118$

$\begin{array}{ll}\text { Objectives, target audiences and research } & 119\end{array}$

Educational initiatives 120

Building a coalition 120

Cultural activities $\quad 121$

Conclusion $\quad 121$

Bibliography - Brazil 122

14 Egypt 123

Research 123

Primary care physicians $\quad 124$

Individuals living with schizophrenia and family members $\quad 124$

$\begin{array}{ll}\text { Journalists } & 124\end{array}$

Interventions $\quad 124$

Working with medical students $\quad 125$

Secondary school students $\quad 125$

Broadening the programme $\quad 125$

Bibliography - Egypt 126

$15 \quad$ Morocco 128

Research 128

Family members and individuals living with schizophrenia 128

Medical professionals 129

Interventions 129

On-going focus on medical professionals 131

$\begin{array}{ll}\text { Conclusion } & 131\end{array}$

Bibliography - Morocco 132

$16 \quad$ United Kingdom 133

Phase One 133

Implementing workshops with police officers 134

Implementing workshops in schools 134

Findings and recommendations $\quad 135$

Phase Two 136

Conclusion 136

Bibliography - United Kingdom 137 
Cambridge University Press

0521549434 - Reducing the Stigma of Mental Illness: A Report from a Global Programme of the World Psychiatric Association

Norman Sartorius and Hugh Schulze

Frontmatter

More information

$\mathbf{x}$

\section{Contents}

17 Working in Partnership - Australia

A wealth of information resources

In collaboration with the media

Award-winning efforts

18

Chile, India and Romania

Chile

Interventions in the psychiatric community 143

Consumers and family members $\quad 144$

Reference - Chile

Bibliography - Chile

India

The importance of family support 145

New initiatives

Educational initiatives

Working with the National Service Scheme 147

Bibliography - India 148

Romania

References - Romania

Structure and flexibility

Target groups

A question of media

Development of messages

Recommendations about principles of programme development

Reference

Afterword

Appendix I

Appendix II

Appendix III

Appendix IV

Index 


\section{Preface}

The Second World War is now becoming a dim memory for all but those who lived it. Among them, those who were not soldiers by profession, civilians caught in the maelstrom of misery, death, terror, starvation and suffering also remember it with particular clarity.

In that war, my mother, a pediatrician, joined the partisans in Yugoslavia and took me along. Although this has been more than half a century ago and I was only 8 -year old I still remember the time we spent with the resistance movement with extraordinary clarity: the years immediately before and after have long receded into vague landscapes of time. Among the memories of the war is one of the nasty winter of 1943 when I had an experience that gained in significance over the years.

We had completed many hours of enforced march and had come to a road that we had had to cross: it was well guarded and it was necessary to wait for a period between the enemy patrols to get to the other side. Everyone had to remain absolutely quiet. We held that position for hours waiting for the signal to proceed. It was there that I saw a cortege, a carriage with six white horses, with attendants dressed in eighteenth century costumes and finery pass by on the protected road. It was quite beautiful and I remember how extremely clear it seemed to me. I heard the sound of the hoofs and muted voices of the attendants. The carriage was moving slowly and once it passed another came along. This hallucination lasted for what seemed a long time. When I pointed to the sight and described it to others they looked at me puzzled and ordered me to stop talking about it.

Over the past few decades a number of new findings contributed to our knowledge about schizophrenia. Some of these relate to morphological changes of the brain observable by the increasingly powerful investigative techniques. Others relate to the nature of the schizophrenic experience, to the importance of maintaining the patients' self-esteem for the process of recovery and to the positive role that families can play in helping the patient if properly trained.

And yet, for all the advances that have been made by the neurosciences, by the social and behavioural sciences, by studies of treatment and by public health investigations the mystery of the brain-mind barrier seems as impenetrable as it always was. Jim van Os and others demonstrated that typical symptoms of 
Cambridge University Press

0521549434 - Reducing the Stigma of Mental Illness: A Report from a Global Programme of the World Psychiatric Association

Norman Sartorius and Hugh Schulze

Frontmatter

More information

\section{Preface}

psychosis appear in people who never consulted a doctor for it with a surprisingly high frequency (Verdoux and Os, 2002): why some of these experiences appear and vanish while others stay or keep coming back and occupy one's mind is still unclear. Why did I see the cortege with white horses when no one else saw it and why did this type of experience never come back even though there were many other situations in which I was exhausted, hungry, sleepy and frightened? And what would have happened to me had I been brought to a hospital, kept there for observation and maybe given some treatment? Could the label of being kept for observation in a mental institution have changed my subsequent schooling, social relationships and working life?

The level of our ignorance is such that it is safe to predict that much more time is necessary before we learn enough about schizophrenia to be able to prevent it. We can however provide care to people who suffer from schizophrenia and know what could enhance the probability that our treatment will be successful and that patients will find their place in society. We know what obstacles stand in the way of recovery and rehabilitation. Among these obstacles undoubtedly the most serious and difficult is the stigmatization of mental illness and of all those in contact with it - the sufferers, their families, the medications used for treatment, the institutions in which treatment is provided, staff in mental health institutions and even the sites on which they are located.

This book is about stigma and ways of fighting it. It reports on what we and the other participants in the WPA Global Programme against Stigma and Discrimination because of Schizophrenia have learned from it. It also contains our thoughts about ways of intensifying the programme and making it an essential part of health services, equivalent in importance to training staff about ways to treat diseases.

We hope that this volume will make readers aware of the nature of stigmatization of mental illness in different cultures and of the consequences of stigma and discrimination for all concerned. We also hope that it will make readers eager to join those who fight these because they are awesome obstacles to progress not only for mental health programmes but also for progress towards the creation of a civil society.

Norman Sartorius

Geneva, Switzerland, 2005

\section{REFERENCE}

Verdoux, H. and van Os, J. (2002). Psychotic symptoms in non-clinical populations and the continuum of psychosis. Schizophrenia Research, 54(1-2), 59-65. 


\section{Introduction}

The stigma attached to mental illness and all that is related to it - patients who suffer from mental disorders, their families, psychiatric institutions, psychotropic medications - is the main obstacle to better mental health care and better quality of life of people who have the illness, of their families, of their communities and of health service staff that deals with psychiatric disorders. It is a basic component of the negative discrimination that people with mental illness experience every day. It blocks access to facilities and options that, in principle at least, have been created to help people impaired by mental illness. Stigma is pernicious and what is worse there are indications that despite advances of psychiatry and medicine stigma continues to grow and has more and more often terrible consequences for patients and families.

The stigma associated with schizophrenia is particularly harsh. A person diagnosed with the illness will be seen by most of those around him or her as dangerous, lazy, incompetent at work, unable to be a family member that fulfills his or her social obligations. Different fears and prejudicial judgments may be in the foreground of stigma in different cultural settings: what is common is that the negative opinion will stay stable even after all the symptoms of the disease have disappeared and after it has been possible to show that the individual concerned can work and fulfill his social roles at least as well as his fellow citizens.

That stigma exists and that it is pernicious is gradually becoming accepted (Link et al., 1992). This growth of awareness is however only rarely accompanied by the commitment or at least willingness to do something about diminishing stigma and its consequences.

The reasons given for inaction by mental health workers (and by others who should be concerned with stigma) are varied. Some say that they are too busy, others that individuals cannot change stigmatization. Still others state that stigma linked to mental illness is not very different from the stigma attached to other illnesses and therefore only a comprehensive programme which is beyond their reach can make sense. 
Cambridge University Press

0521549434 - Reducing the Stigma of Mental Illness: A Report from a Global Programme of the World Psychiatric Association

Norman Sartorius and Hugh Schulze

Frontmatter

More information

xiv Introduction

\section{The different voices of stigma and discrimination}

During the course of the programme in interviews, in focus groups and more public forums, those living with the illness and their families have described many different ways stigma and discrimination is manifested:

From India: 'My parents support me but we can't tell any of our neighbors. It would hurt my sister's chances of being married.'

From Canada: 'If I apply for the job and tell them I have schizophrenia, I won't be hired. If I don't tell them and they find out, or I suffer a relapse later, I will be fired.' From Japan: 'Women with an illness like this will be kept at home to do domestic chores, while we men are sent out of the house.'

From the United Kingdom: '[T]he only way I found out the doctors had diagnosed me with schizophrenia was because I managed to read it upside down on my medical notes! No one had told me and finding out that way was very frightening. I felt very alone.'

From the United States: 'The doctors left me waiting in the emergency room, fighting my delusions for six hours; they said other people's problems were more serious than mine.'

\section{The Global Programme of the World Psychiatric Association}

In 1996, the World Psychiatric Association undertook a programme to address the stigma and discrimination because of schizophrenia. At a meeting in Geneva, Switzerland, 38 psychiatrists from more than 20 countries and representatives from consumer groups discussed ways to address the barriers to proper treatment, the difficulties with reintegration, and how best to address the human rights of those living with the illness and of their families.

Collectively, the group agreed to three guiding principles for the programme:

- to survey individuals living with the illness and their family members about the experience of stigma and discrimination, and where possible encourage their active participation;

- to encourage the participation of individuals throughout the community whether in health care, government or private enterprise - everyone was welcome;

- to ensure this was a long-term effort, rather than a brief campaign.

To start the programme it was necessary to develop guidelines and manuals. Initially, these would be drafts which would be improved upon in the course of time. To produce those materials the Steering Committee established four other groups: 
Cambridge University Press

0521549434 - Reducing the Stigma of Mental Illness: A Report from a Global Programme of the World Psychiatric Association

Norman Sartorius and Hugh Schulze

Frontmatter

More information

The Treatment Committee was charged with compiling the latest information on the illness and the variety of treatment options available. For the first year, the head of this group was the Italian psychiatrist, Mario Maj. In 1997, Wolfgang Fleishhacker of Austria stepped into that role.

The Reintegration Committee, chaired by Julian Leff of the UK, was to examine results of research done on reintegrating individuals back in society.

The Stigma Committee, the largest of the four groups, surveyed the manifestations of stigma and discrimination because of schizophrenia in different cultures and countries. Richard Warner from the US directed the efforts of that group.

Finally, while the programme's Steering Committee oversaw the interworking of the groups, the Review Committee would review the documents produced by the groups.

After reviewing the evidence and relevant facts, the groups produced a single volume on schizophrenia. The volume was written in the style of an encyclopedia entry, easily readable and based on evidence. The volume was annotated with remarks indicating sections particularly relevant to fighting stigma. This volume was meant to provide a central compendium of the latest scientific information on schizophrenia for the media and programme participants. This volume has been translated into Spanish, Polish, Italian and Japanese. In Spain, it has been published as a book.

The groups next produced a step-by-step guide for implementing an anti-stigma programme. The group understood that most of the implementers of the programme in individual countries would have had little or no experience in addressing public awareness or changing public opinion and wanted to provide guidance on social marketing efforts. That volume was drafted by Dr Sartorius and Dr Hugh Schulze with the help of Dr Warner, and reviewed by the Steering Committee and other experts, such as communication professionals. It is designed to assist psychiatrists and other mental health professionals in assembling a Local Action Group, setting measurable goals and objectives, and identifying key target groups for the programme. The guide includes suggestions on how to hold a press conference, write a press release, and numerous other practical tips. After years of its use, the volume has been further developed through the creation of a Manual with practical suggestions based upon the experiences of the programme and use of the volume.

The steps outlined in that initial volume take Local Action Groups roughly 12 to 18 months to implement - from initial planning meetings to full implementation. Over the years, a number of general principles have emerged that have applied in all countries:

- The programme's goals should be based upon information obtained from patients and their families in the culture in which they live. 
Cambridge University Press

0521549434 - Reducing the Stigma of Mental Illness: A Report from a Global Programme of the World Psychiatric Association

Norman Sartorius and Hugh Schulze

Frontmatter

More information

xvi

\section{Introduction}

- The programme should be directed at particular, defined target groups.

- The programme should be undertaken first in areas in which success is likely in the short term to encourage all participants.

- The programme should include active participants willing to stay with the programme for at least 2 years.

- The Local Action Group should develop a plan of action and invite leading personalities in the country to join the programme's support group.

- The programme will place all of its experience and funding at the disposal of other programmes participating in the global effort, and in turn rely upon their resources when and where necessary.

- When identifying select target groups it is important to have an individual from that particular target group on your team - not only can they provide insights on the best way to address their peers, but recommendations on individuals and groups you may be unaware of.

- For national programs, a group composed of representatives from the different cities or regions is important to ensuring coordination between the groups and amortizing costs overall.

- In general, the more targeted the intervention - in terms of messages and media directed to identifiable individuals or a group - the more effective the effort will be. (We will see examples of this in the Canadian Pilot Study.)

The volume also contained practical suggestions such as the creation of a project log, establishment of regular meeting times and other suggestions for maintaining group cohesion. Examples from both volumes are listed in the appendices of this book.

Since that first meeting, more than 20 countries have undertaken nearly 200 anti-stigma interventions. As we will see, these interventions were directed towards well-defined target groups in an effort to address different parts of the vicious cycles that lead to discrimination and prejudice.

The WPA and Local Action Groups in different countries have published journal articles and reports on the on-going efforts around the world. They have also made presentations at major scientific meetings, conferences and congresses. This book is intended to gather the latest data from all of these efforts and provide insights into how each initiative was developed in a particular country through the cooperation of men and women from a wide variety of backgrounds.

What sets this programme apart from other anti-stigma initiatives is both its international nature - whereby groups in different countries were able to share best practices - and the collaborative nature of the Local Action Groups. Following guidelines set out by the WPA Global Programme and refined in other countries, these groups bring together psychiatrists and other mental health professionals, 
Cambridge University Press

0521549434 - Reducing the Stigma of Mental Illness: A Report from a Global Programme of the World Psychiatric Association

Norman Sartorius and Hugh Schulze

Frontmatter

More information

journalists, politicians, schoolteachers, and perhaps most notably, those living with schizophrenia and their family members as well.

The First International Conference on the Stigma and Discrimination because of Schizophrenia was held in Leipzig, Germany in 2001. In 2002, further findings were presented at the WPA Congress in Yokohama, Japan, a logical consequence of the fact that the Global Programme against Stigma is one of the five Institutional Programmes of the WPA. A Second International Conference was held in Kingston, Ontario in Canada in 2003. It is expected that further conferences dealing with the work against stigma and its consequences will take place and that they will allow an exchange of experience at the same time as an encouragement to those participating in the programme and others that will join them. 
Cambridge University Press

0521549434 - Reducing the Stigma of Mental Illness: A Report from a Global Programme of the World Psychiatric Association

Norman Sartorius and Hugh Schulze

Frontmatter

More information

\section{Structure of this Book}

The opening chapter provides an overview of the challenge and methodologies used to fight stigma and discrimination. The following chapters provide country-specific reports on interventions undertaken following the WPA guidelines. These have been organized more or less chronologically in four phases. Phase I, which involved the first use of Volumes I and II of the programme materials, was undertaken in 1997 in Calgary, Canada. Phase II was an extension of the programme to Spain and Austria. Phase III included other European countries such as Germany. Phase IV was programme implementation in other countries.

Each chapter concludes with a list of articles relevant to the anti-stigma efforts in that country. The final chapter includes a list of recommendations and cautions relevant in undertaking such a programme. In Appendix I, the reader will find Volume I of the programme - a step-by-step guide to planning and implementation. Appendix II contains sample pages from Volume II, which contains information on the diagnosis and treatment of schizophrenia, along with a section devoted to the stigma and discrimination associated with the illness. We have also included the instruments for surveys of knowledge and attitudes that were used in the Calgary Pilot Study in Alberta, Canada.

Additional information is available at the programme web site:

\section{www.openthedoors.com}

Those interested in starting a programme against stigma should contact:

Professor Dr Norman Sartorius

14 chemin Colladon

1209 Geneva, Switzerland

Tel: 41227882331

Fax: 41227882334

E-mail: mail@normansartorius.com

Please note that those who join the WPA network will be expected to share the data that they obtain in their work with other participating sites and to follow the guidelines of the programme. In turn they will be given access to all of the sites' materials and will be kept informed about the development of the programme.

xix 
Cambridge University Press

0521549434 - Reducing the Stigma of Mental Illness: A Report from a Global Programme of the World Psychiatric Association

Norman Sartorius and Hugh Schulze

Frontmatter

More information

\section{Participants in the Programme}

This programme was developed by experts from many countries, non-government organizations, associations of patients and their families, as well as government representatives.

\section{Steering Committee}

Norman Sartorius (Switzerland): Scientific Director

Juan J. López-Ibor (Spain)

Julio Arboleda-Flórez (Canada)

Ahmed Okasha (Egypt): Chairman

Hugh Schulze (United States)

Costas N. Stefanis (Greece)

Narendra N. Wig (India)

\section{Treatment Committee}

W. Wolfgang Fleischhacker (Austria): Chairman after 5/97

Juan J. López-Ibor (Spain): Steering Committee Representative

Timothy J. Crow (United Kingdom)

Paramanand Kulhara (India)

Jan Libiger (Czech Republic)

Michael G. Madianos (Greece)

Mario Maj (Italy): Chairman through 5/97

Michael O. Olatawura (Nigeria)

\section{Reintegration Committee}

Julian Leff (United Kingdom): Chairman

Costas N. Stefanis (Greece): Steering Committee Representative

Marina Economou (Greece)

Wolfgang Gaebel (Germany)

Ulf Malm (Sweden)

Vincent B. Wankiiri (Uganda)

xxi 
Cambridge University Press

0521549434 - Reducing the Stigma of Mental Illness: A Report from a Global Programme of the World Psychiatric Association

Norman Sartorius and Hugh Schulze

Frontmatter

More information

\section{xxii Participants in the programme}

\section{Stigma Committee}

Richard Warner (United States): Chairman

Narendra N. Wig (India): Steering Committee Representative

Anthony W. Clare (Ireland)

Sue Ellen Estroff (United States)

Julio Arboleda Flórez (Canada)

Robert Freedman (United States)

Semyon Gluzman (Ukraine)

Trisha Goddard (Australia)

Driss Moussaoui (Morocco)

Michael Phillips (China)

Everett M. Rogers (United States)

Corinne L. Shefner-Rogers (United States)

\section{Review Committee}

Wolfgang Gaebel (Germany): Chairman

Heinz Häfner (Germany): Chairman to 2001

Norman Sartorius (Switzerland): Steering Committee Representative

Istvan Bitter (Hungary)

Giovanni de Girolamo (Italy)

R. Srinivasa Murthy (India)

Ahmed Okasha (Egypt)

Charles Pull (Luxembourg)

Wulf Rössler (Switzerland)

Pedro Ruiz (USA)

Mitsumoto Sato (Japan)

Harold M. Visotsky, deceased (United States)

Greg Wilkinson (United Kingdom)

ex officio Review Committee Members

W. Wolfgang Fleischhacker (Austria)

Julian Leff (United Kingdom)

Richard Warner (United States)

\section{Chairpersons and Advisors of Local Action Groups}

Each chapter of this book is dedicated to a different initiative in a different country. At the end of each country report, we will list many of those who have helped make those programmes a success. Here, we wish to acknowledge those heads of sites 
Cambridge University Press

0521549434 - Reducing the Stigma of Mental Illness: A Report from a Global Programme of the World Psychiatric Association

Norman Sartorius and Hugh Schulze

Frontmatter

More information

instrumental in bringing the results to this book. Contact information for individuals and Local Action Groups are given at the end of appropriate chapters. (Like the chapters themselves, the countries are listed in chronological order roughly corresponding to when the initiatives were begun.)

$\begin{array}{ll}\text { Canada } & \text { Julio Arboleda-Flórez and Heather Stuart } \\ \text { Spain } & \text { Juan J. López-Ibor and Olga Cuenca } \\ \text { Austria } & \text { Werner Schöny and Wolfgang Fleishhacker } \\ \text { Germany } & \text { Wolfgang Gaebel and Anja Baumann } \\ \text { Italy } & \text { Guiseppe Rossi } \\ \text { Greece } & \text { Costas Stefanis and Marina Economou } \\ \text { United States } & \text { Richard Warner } \\ \text { Poland } & \text { Andrzej Cechnicki and Anna Bielánska } \\ \text { Japan } & \text { Mitsumoto Sato } \\ \text { Slovakia } & \text { Pětr Nawka } \\ \text { Turkey } & \text { Alp Üçok } \\ \text { Brazil } & \text { Cecilia Villares } \\ \text { Egypt } & \text { Tarek Okasha } \\ \text { Morocco } & \text { Nadia Kadri and Driss Moussaoui } \\ \text { United Kingdom } & \text { Graham Thornicroft and Vanessa Pinfold } \\ \text { Australia } & \text { Barbara Hocking and Alan Rosen } \\ \text { Chile } & \text { Carlos Caceres Gonzalez } \\ \text { India } & \text { R. Srinivasa Murthy and R. Thara } \\ \text { Romania } & \text { Raluca Nica }\end{array}$


Cambridge University Press

0521549434 - Reducing the Stigma of Mental Illness: A Report from a Global Programme of the World Psychiatric Association

Norman Sartorius and Hugh Schulze

Frontmatter

More information

\section{Acknowledgements}

This programme would not have been possible without the generous support of many people living with schizophrenia and their families in more than 20 countries around the world, including the family associations that support them. The programme has also been supported by medical and psychiatric institutions, and other agencies many of whom are listed in the appropriate country reports.

We would also like to thank Eli Lilly and Company who have generously supported both the international effort and local initiatives in some countries.

The authors would also like to thank Josette Mamboury in Geneva, Switzerland and Melissa Woods in Chicago, United States for their invaluable assistance in this programme over the years. 